\title{
I KNOW READ AND COUNT BUT I DON'T KNOW: A SPECIAL HISTORY AND SUI GÉNERIS
}

\author{
Edward Enrique Rojas de la Puente \\ Toribio Rodríguez National University of Mendoza, Peru \\ Guido Ayay Arista \\ Toribio Rodríguez National University of Mendoza, Peru
}

\begin{abstract}
We describe the sui generis case of a couple of cohabitants and parents of 9 children that stands out in the light of the cognitive admiration and applause of many, because it shows how our characters considered illiterate in the eyes of the conventional educational world, arrived to be regular readers without having attended an educational center. The purpose of the study is to highlight the circumstances that forced the subjects of the sample to start alone in the field of reading. As a method, mayicatica was applied and the observation technique was used whose instruments were observation records and structured interviews. In conclusion, the collected experience shows that the learning of reading is not only conventional and its acquisition also responds to real communication needs.
\end{abstract}

Keywords: literacy, illiteracy, learning, writing and reading.

\section{Introduction}

The present case study, scientifically named, is based on neurological approaches to understand the personal history of Mr. Francisco Gómez Cabañas, a native of the district of Velapata, Chachapoyas - Amazonas, Peru and his wife Mrs. Adelina Vargas Trigoso. This case is unique or unique, which deserved to be studied for many reasons and among them we mentioned the following: Knowing how to read without knowing how to write, knowing how to count money without knowing how to add; something anecdotal and striking because it fractures or breaks with the conventional patterns or schemes of teaching reading and writing which argue that to read it is necessary to know how to write and that to add it is essential to know the elementary numbers and operations. The study aims to highlight the empirical procedures and circumstances that forced these people to start alone in the field of reading.

The world's educational systems have the agreed opinion that children should be taught to read and write; This action is totally accepted in diverse cultures. For example, according to Spanish regulations, the ideal age to start going to school is between 18 and 24 months, in Peru and much of Latin America, the minimum age is 3 years for Initial and 6 years for Primary. (Ministry of Education of Peru, 2017) 
In general, it is assumed that education and the right to education must begin within two or three years; since, at that age the child begins to have autonomy, he can already walk, emit words and begins in the learning of reading and writing through training; Upon reaching the age of six, the child must now fully manage the conventional reading and writing system. In this regard, numerous investigations open debate and try to find out scientifically what is the ideal age of the child in which to learn the system of conventional reading and writing. In this sense, the Ministry of Education of Peru (2015), determines that the school has the function of guaranteeing the acquisition of the graphic system of linguistic representation, from the level of Initial and is consolidated in the first cycle of Primary. Therefore, teaching to understand and rebuild the alphabetical writing system is a priority of the educational system.

\section{Approaches to reading and writing}

Three are the most common approaches that to date have been considered as educational proposals in initial literacy and that explain reading and writing differently (Vernon, 2013). First, the approach called "direct teaching" considers that a child must learn to identify the sounds with the corresponding letter, which is known as "phonological awareness" (Defior, 1994); likewise, he explains that the acquisition of phonological skills allows for good social communication. Proponents of this approach agree that our alphabetical writing system is a transcription of sounds and that the acquisition of phonological skills serves as the basis for learning to read and write (Defior, 1994). Secondly, there is the "integral language" approach (Goodman, 1989) in which it is stated that the learning of written language is a "natural" learning, since any child learns to speak without being taught explicitly to do so, since it is surrounded by people who use their language to communicate. Likewise, Goodman (1989) considers that the child who lives in a social environment that uses writing as a means of communication will learn to read and write because he needs to communicate. And finally, the constructivist approach (Ferreiro, 1990) that shares some points with integral language, especially the idea that reading and writing are communicative activities, and that children should come into contact with different types of texts from the beginning. In the same way, according to Teberoski (1992) both share the notion that reading is not decoding, but searching for meaning.

\section{Illiteracy and literacy}

Illiteracy is a worrying reality anywhere in the world, especially in developing countries. Many works on illiteracy allow us to indicate that there is 
no single way to define illiteracy and its types, nor the exact form of its measurement (Chapital, 2015). The terms such as "no study", "no instruction", or "low or null schooling" are used to replace that of "illiterate people" or "who cannot read or write" (Pineda \& Chapa 2018). However, the common denominator of its definition seems to be that given by the Organization of IberoAmerican States (OEI) who defines it as the ignorance of literacy and basic arithmetic notions, which is linked to de-schooling (OEI, 2010). Meanwhile, illiterate people are understood to be those who do not know the coding and decoding of the written alphabet, so they cannot handle it widely to read and write, which does not prevent them from relating in literate practices and using written materials. (Pineda \& Chapa 2018)

On the other hand, beyond its conventional concept as a set of reading, writing and calculation skills, or as an absolute or functional illiteracy (Martínez \& Fernández, 2010), literacy today is understood as a means of identification, understanding, interpretation, creation and communication in an increasingly digitalized world, based on texts and rapidly evolving.

In Latin America and the Caribbean, significant progress has been made in terms of expanding coverage and educational access (Martínez, Trucco, \& Palma, 2014). However, despite these advances and that absolute illiteracy rates are close to those of developed countries, there are still 35.9 million people over 15 who are illiterate (UNESCO, 2013). Such a reality, leads to the exclusion of young people and adults who, because they consider themselves poorly trained or qualified, cannot fully integrate into their community or immediate environment.

Consequently, the OEI (2010) indicates that "illiteracy is one of the most serious expressions of the process of exclusion and social marginalization, and, therefore, literacy is an essential requirement in any equity and social inclusion strategy" (p. 2). In that logic, literacy brings a series of advantages to those who have access, as well as to the communities and nations in which they develop. Among these advantages, according to Del Valle (2016), benefits of different types stand out: human benefits, linked to self-esteem, self-confidence and personal autonomy; cultural benefits, enabling the development and acquisition of critical and reflective capacity and allowing participation in the cultural life of the group; social benefits, improving knowledge in health, family planning, preventive measures to prevent diseases, etc., and economic benefits, enabling the increase of personal income, as well as promoting economic growth in the country itself.

\section{Processes in literacy and inborn levels in their learning}

For Vygotsky (1931/1995) the learning of written language consists in appropriating a system of symbols and signs, whose achievement determines the 
child's cultural development. For their part, Montealegre and Forero (2006) determine that the development of literacy goes from non-awareness of the relationship between writing and spoken language, to the process of conscious operations such as the individualization of phonemes, the representation of these phonemes in letters, the synthesis of letters in the word, the organization of words; to the automation of these operations; and to the mastery of written text and written language.

In the development of literacy, Montealegre and Forero (2006) explain that there is a sequence of acquired processes such as: a) the development of written language as a natural form; b) the use of auxiliary signs in the assimilation of written language; c) levels of conceptualization or levels of literacy awareness: alphabetic awareness, phonological awareness, syllabic awareness, semantic awareness and syntactic awareness (ordering in oral discourse); d) the development of oral language and proper pronunciation as determinants in literacy learning; e) the process of learning literacy in natural (eg, game) and social (conversation activities) contexts; f) the teaching of literacy in a functional way and immersed in culture and daily life; and g) the potential of boys and girls in the construction of schemes (knowledge structures) on reality data.

\section{Methodology}

The present investigation is a case study conducted with two illustrious natural characters from the province of Chachapoyas-Peru, Don Francisco Cabaña and his wife Adelina Vargas; it is a unique case that arouses admiration in the reader; since, they are considered as illiterate before the conventional educational system; However, in their daily lives they became regular readers without having attended an educational center, breaking the different conventional schemes imposed on literacy systems.

This reality led us to formulate a scientific problem, study the relevant theories, and then find results with empirical evidence. As a method of investigation, the maieutics was applied, since, by means of questions, knowledge was discovered. As a technique, observation was used, whose instruments were reflected in observation records and structured interviews.

Data collection was carried out from 2015 to mid-2019. To do this, the field work consisted of home visits together with students of the Language, Language and Communication Theory courses taught at the Toribio National University Rodríguez de Mendoza, in different Professional Schools. 


\section{Results of the research}

Our character was born in the annex of San Miguel de Velapata (former estate of the Tuesta López family), district of the province of Luya (ChachapoyasPeru), on October 4, 1923 whose wife is Mrs. Adelina Vargas Trigoso with whom they had 9 children of the schools died 7 and today two (Juana and Ramón) live their childhood and adolescence was spent working in this hacienda of San Miguel de Velapata, performing domestic work, agriculture and livestock work. He attended school, but after two months he retired because he could not continue to do housework in such a way that he did not learn to read and write and less to add; that is, he did not learn the alphabetic method to learn to write and neither did the phonetic method to learn to read, let alone the syllabic method; these methods consist: the first one learning the sound of the alphabet, the words are formed by combining the vowels and consonants; the second is the phonetic method in which vowels and consonants with the image of the object and the word are learned. Then consonants are combined with vowels, thus giving sequences of syllables such as: pa - pe - pi - popo, and finally the syllabic method that considers the syllable as the minimum unit of learning.

The syllabic method considers in a basic way the learning of the vowels and then they combine consonants with vowels, also the other way around, later turning to words that combine presented syllables and then phrases.

Don Francisco never had the opportunity to learn any method to learn to read and write, he only saw the letters, but he never got to memorize them like all school children who know the alphabet are upside down and straight, also combine vowels with syllables so playful We can say and affirm that he did not learn to read and write in short. As for adding, Don Francisco met and came to identify some numbers, but failed to perform the basic operations that are: add, subtract, multiply and divide.

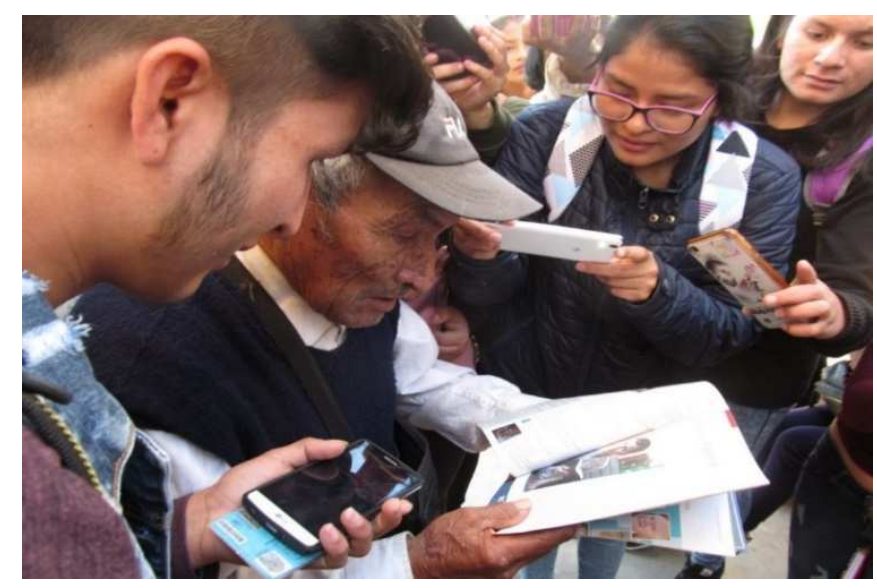

Figure 1 Psychology students observe surprised how Don Francisco Gómez Cabañas reads any type of text 
Rojas de la Puente \& Arista, 2020. I Know Read and Count but I Don't Know: a Special History and Sui Géneris

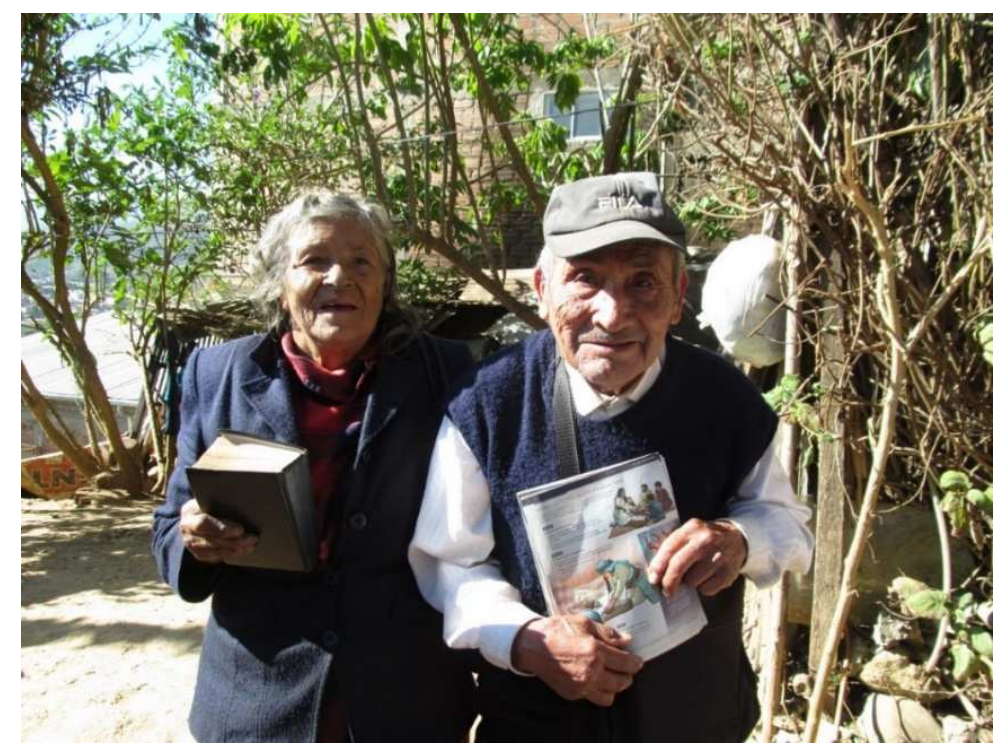

Figure 2 Don Francisco and his wife demonstrating their "Awake" magazines, preferred for reading

Don Francisco is currently 96 years old and lives in the company of his family, daughter, grandchildren and great-grandchildren. The life of such a distinguished, special and unique character is of simplicity and moral order and of love and respect for God as shown in the illustrations presented. He is much appreciated, respected, loved and admired for his great determination and effort of a totally exemplary life by many young people who sporadically visit him to learn from him.

a)

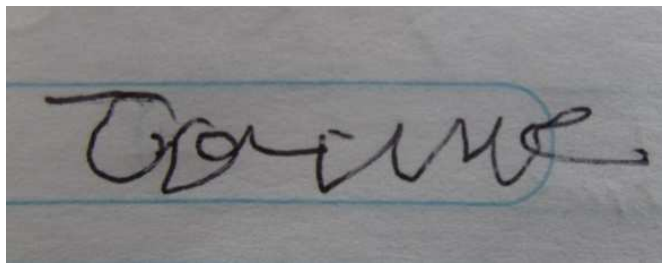

c)

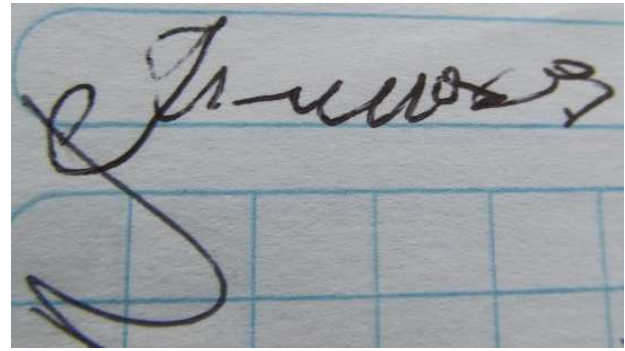

e)

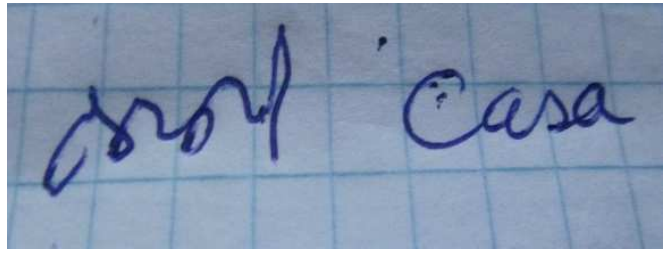

b)

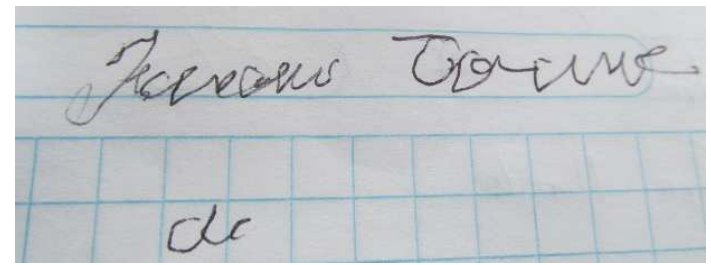

d)

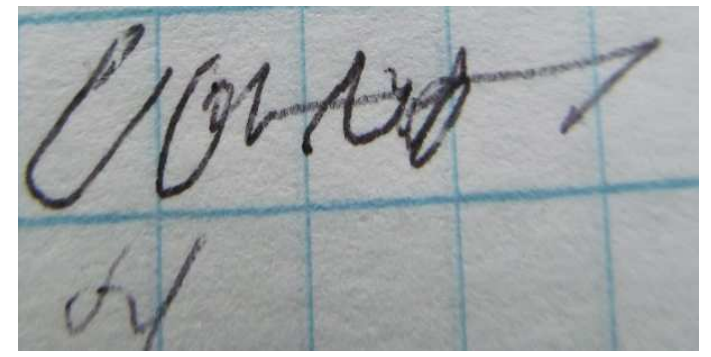

f)

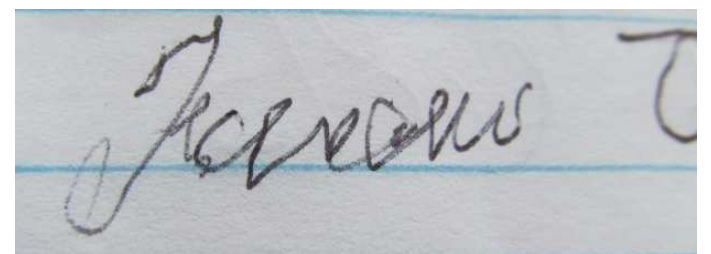


g)

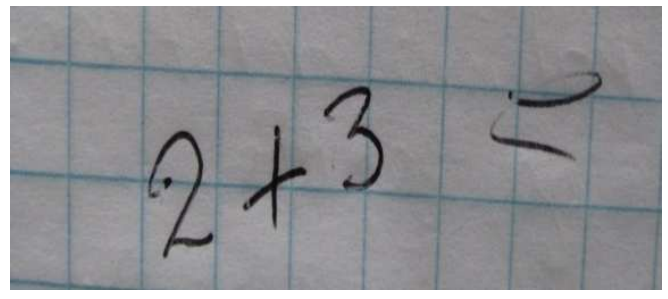

h)

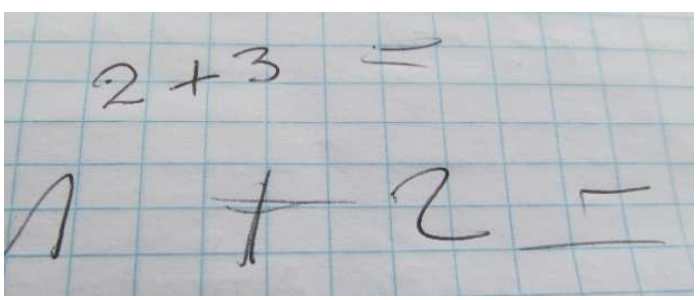

Figure 3 The images $a, b, c, d, e, f, g$ and $h$, are photos taken on different dates visited by Don Francisco (periods 2015-2019)

As shown in illustration 3, the different images presented represent the level of writing of our characters. At each visit they were asked to write some words or numbers and to perform calculations. To our amazement, they cannot do them if it is writing and they cannot add in the cases of written numbers; However, when any type of text is presented, its reading is fluid and the mental operations of calculation are also astonishing.

Conversing with him is amazing, exciting and we could even say magical because it breaks with the traditional teaching of reading and writing. At the end of reading this real case, dear reader, ask yourself the following question: Is our real character, Don Francisco Gómez Cabañas illiterate and ignorant?

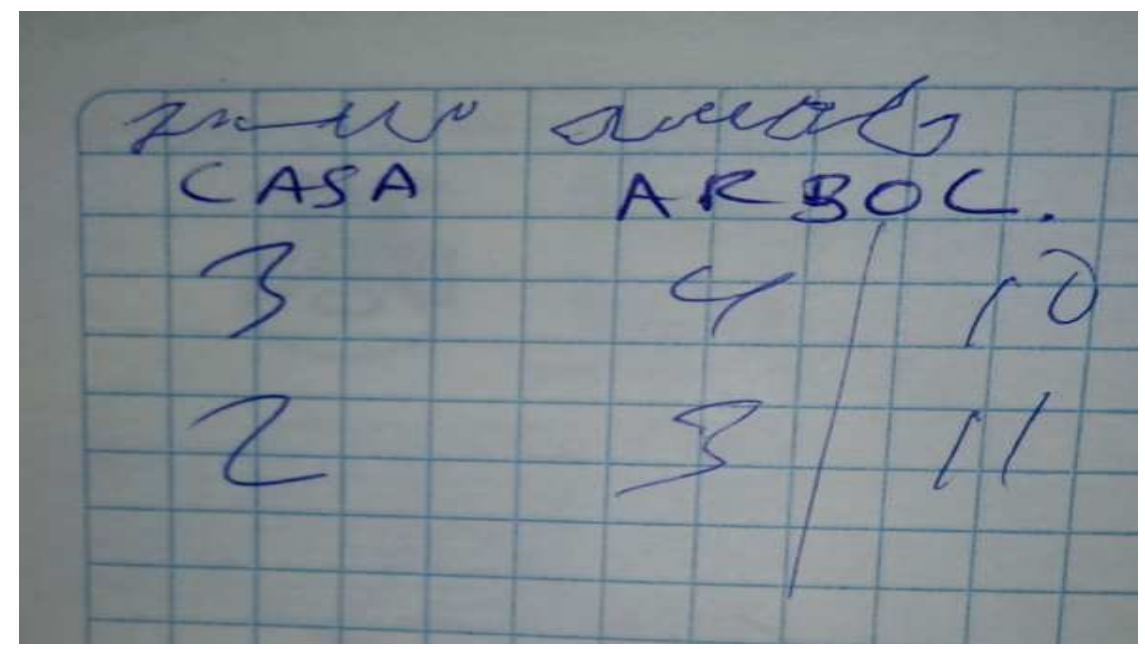

\section{Figure 4 Strokes made by Don Francisco in the upper left that mean house and tree}

In figure 4, the numbers 3 and 2 are also observed 4 and 3 in which we ask you to add and evidenced that it is not possible to perform said calculation and say how much it is, but when we told you to count money provided by us, yes $\mathrm{He}$ knew how to do it without minor difficulty. This has been done in the presence of numerous students from different careers of the Toribio Rodríguez de Mendoza National University of Amazonas. 
Rojas de la Puente \& Arista, 2020. I Know Read and Count but I Don't Know: a Special History and Sui Géneris

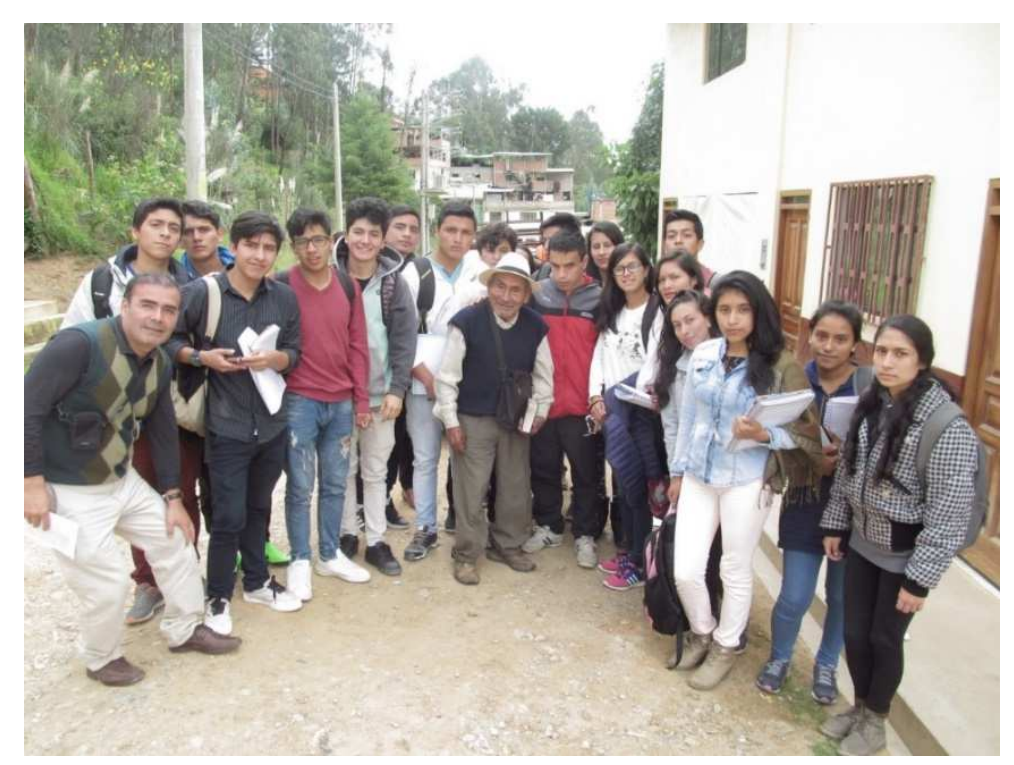

Figure 5 Don Francisco Cabaña Gómez surrounded by students of the UNTRM

Each visit to Don Francisco Cabaña Gómez and his wife Adelina Vargas Trigoso, students are surprised by the reading skills and level of understanding achieved by this illustrious character, who without knowing how to write learned to read and add and be able to integrate into society as a religious entity.

\section{Conclusions}

In general terms, the experience gathered with Don Francisco Cabaña Gómez and his wife Adelina Vargas Trigoso demonstrates that the learning of reading is not only conventional, but can also be developed as long as they are generated in specific situations and respond to real needs of communication that unfold cognitive processes and their self-regulation.

\section{References}

Chapital, O. (2015). Illiteracy: its concept in the world and its way of calculating the construction of indicators. Mexico: INEE (National Institute for the Evaluation of Education).

Defior, S. (1994). Phonological awareness and learning to read and write, Journal for the Study of Education and Development, 17(68), 91-113. DOI: 10.1174/021037094321268886

Del Valle, M. (2016). Education for all: Literacy for all. A worldwide vision [Datafile]. Retrieved from http://www.uco.es/ ed1alcaj/polieduca/dmpe/grupo34.htm

Ferreiro, E. (1990). Literacy in process. Literacy process Literacy in process. Buenos Aires: Latin American Editor Center.

Goodman, K. (1989). Integral language. Caracas: Venezuelan Editorial. 
Martínez, R., \& Fernández, A. (2010). Social and economic impact of illiteracy: model of analysis and pilot study [Datafile]. Retrieved from http://repositorio.cepal.org/ bitstream/handle/11362/3747/S2009862_en.pdfsequence=1\&isAllowed=y

Martínez, R., Trucco, D., \& Palma, A. (2014). Functional illiteracy in Latin America and the Caribbean Panorama and main policy challenges. Santiago: United Nations.

Minedu. (2015). What and how do our students learn? Learning paths; VII Cycle Communication area curriculum. Lima, Peru: Ministry of Education.

Minedu. (2017). Pedagogical proposal for capacity development. Lima, Peru: National Directorate of Initial and Primary Education-DINEIP.

Montealegre, R., \& Forero, L.A. (2006). Development of literacy: acquisition and mastery. Colombian Psychology Act, 9(1), 25-40. Retrieved from https://editorial.ucatolica. edu.co/index.php/acta-colombiana-psicologia/article/view/410

OEI Organization of Ibero-American States. (2010). Ibero-American Plan for Literacy and Basic Education for young people and adults 2007-2015. [Datafile]. Retrieved from http://www.oei.es/alfabetizacion/b/DOCBASE\%20PIA.pdf

Pineda, R.P., \& Chapa, J.B. (2018). Exclusion of illiterate people in the labor relationship. Mexican Journal of Sociology, 80(4). Retrieved from https://www.redalyc.org/ jatsRepo/321/32158243002/html/index.html\#B25

Teberoski, A. (1992). Learning to write. Barcelona: ICE / Horsori.

UNESCO United Nations Educational and Scientific Organization. (2013). Literacy and education. Lessons from innovative practice in Latin America and the Caribbean. Chile: UNESCO.

Vernon, S. (2013). Three different approaches in the initial literacy proposals [Datafile]. Retrieved from https://www.dgespe.sep.gob.mx/public/pemde/lectura/tdea.pdf

Vigotsky, L.S. (1931/1995). The prehistory of the development of written language. In L.S. Vygotsky, History of the development of higher psychic functions, Selected Works III, (pp. 183-206). Madrid: Learning Visor. 